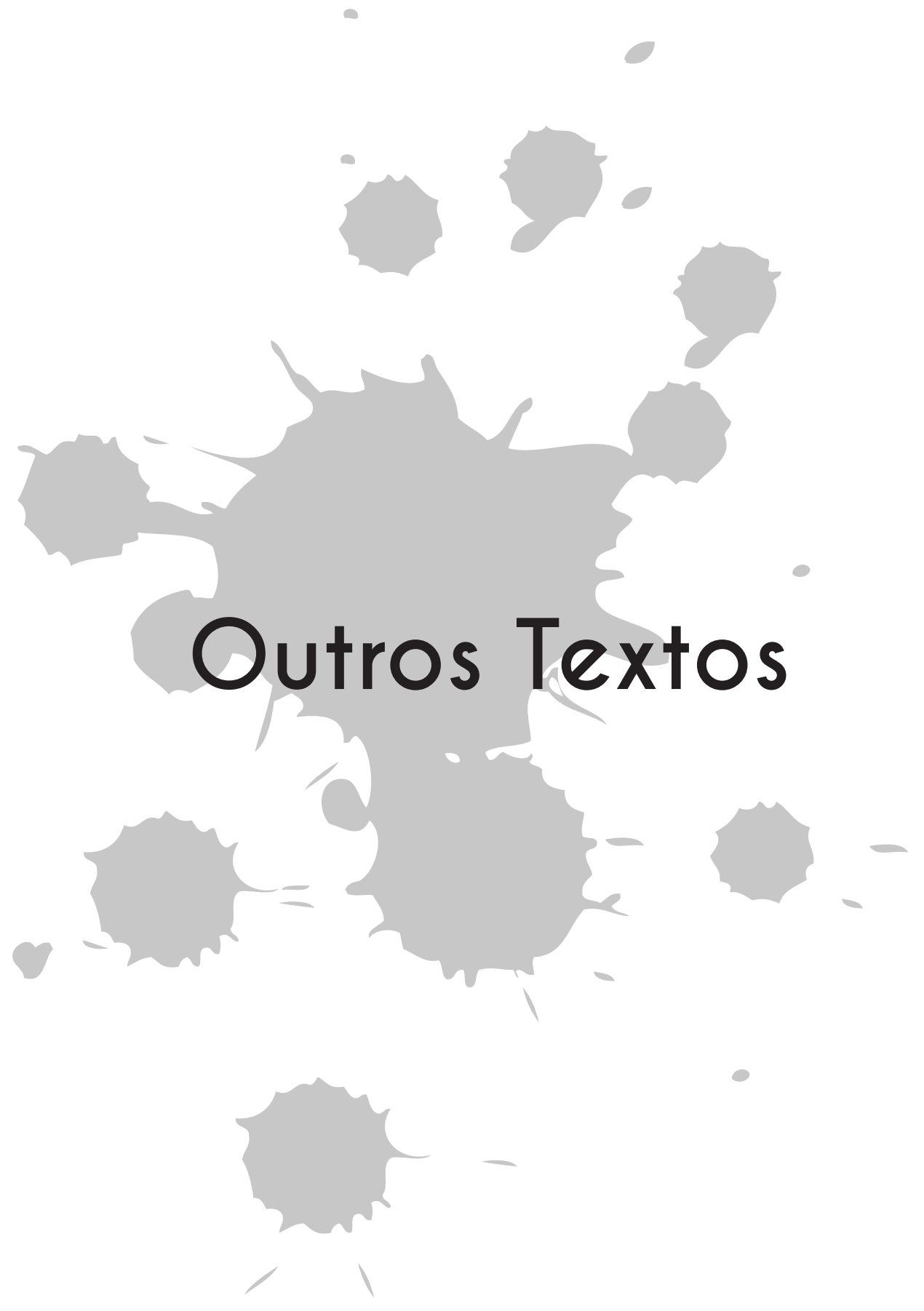




\title{
A guerra como tema e escrita como arma: a juventude sonhadora de A geração da utopia, de Pepetela
}

\author{
The war as a subject and the written word as a \\ weapon: the dreamy youth of Pepetela's $A$ geração \\ da utopia
}

\author{
Glaucia Regina Fernandes* \\ Fabiana Carelli**
}

Resumo: Este artigo pretende discutir de que maneira a juventude angolana da década de 1960 se preparou para a guerra que gerou a libertação de Angola. Dois elementos essenciais norteiam o texto, são eles: a guerra como acontecimento histórico que rege a narrativa e a função da literatura durante esse período.

Abstract: This article discusses how the Angolan youth of the 60s prepared for the war that led to the liberation of Angola. Two elements that guides the text are the war as an historical event, which governs the narrative and the function of literature during this period.

Palavras-chave: Literatura, Guerra colonial, Angola, Pepetela.

Keywords: Literature, Colonial War, Angola, Pepetela.

\footnotetext{
* Mestranda do Programa de Estudos Comparados de Literaturas de Língua Portuguesa da USP.

** Docente-pesquisadora do Departamento de Letras Clássicas e Vernáculas e do Programa de Pós-Graduação em Estudos Comparados de Literaturas de Língua Portuguesa da Universidade de São Paulo.
} 


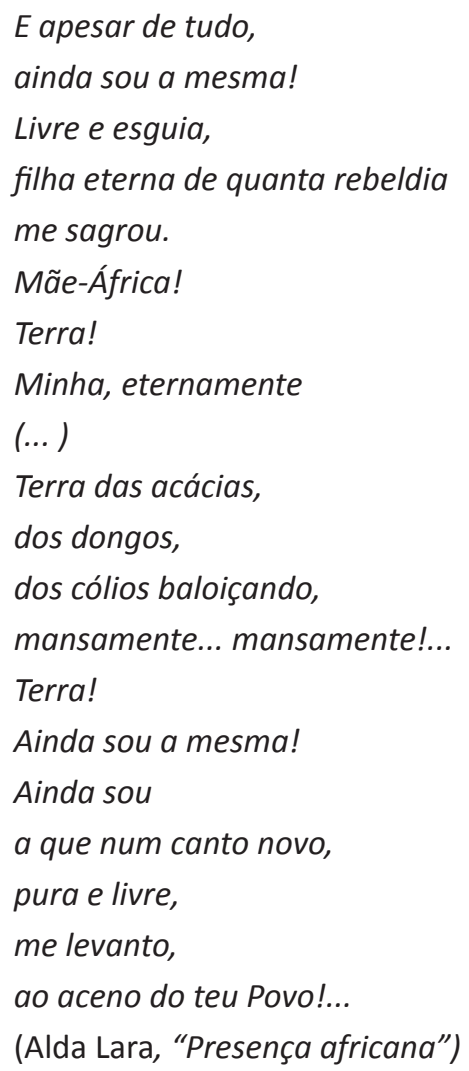

Alusões à África portuguesa surgem logo após a chegada dos colonizadores (século XV). Os primeiros escritos foram de portugueses, mais especificamente os viajantes que percorriam lugares pouco explorados anteriormente, realizando suas rotas pela África, depois pela Ásia, Oceania e Américas. Nesse período, os lusitanos consideravam a África um lugar exótico, com fauna e flora totalmente diferentes das de Portugal, com uma população muito peculiar, em que costumes e cultura Ihes pareciam desconhecidos e pagãos. Nesse tempo, os portugueses já tinham uma vasta produção literária, razão pela qual o país foi considerado um dos mais importantes polos da literatura europeia, e por conta disso, alguns escritores imprimiram suas visões sobre a África em seus trabalhos. No livro de Manuel Ferreira, Literaturas Africanas de Expressão Portuguesa (1977), encontra-se o seguinte relato: 


\begin{abstract}
A historiografia e a literatura portuguesas, sob a óptica expansionista, testemunham o < esforço lusíada 》> da época renascentista. Cronistas, poetas, historiadores, escritores de viagem, homens de ciência, pensadores, missionários, viajantes, exploradores, enobreceram a cultura portuguesa e, em muitos aspectos colocaram-na ao nível da ciência e das grandes literaturas europeias (p. 11, grifo do autor).
\end{abstract}

Ocorre, então, a expansão da produção literária de Portugal ao longo dos "bárbaros reinos", e assim, tem-se uma série de obras relatando as aventuras em terras africanas. Vale ressaltar um importante dado levantado por Manuel Ferreira:

É evidente que esta literatura, nascida de uma experiência planetária, numa época em que o mundo cristão reconhecia o direito à dominação, à depredação e até à barbárie (a cruz numa mão, e espada noutra) nada tem a ver com a literatura africana de expressão portuguesa. Este registro destina-se apenas ou, sobretudo, a retermos factos longinquamente relacionados com o quadro cultural e político que, séculos depois, havia de surgir (FERREIRA, 1977, p. 12).

Da segunda metade do século XIX até o início do século XX alguns escritores angolanos iniciaram uma acanhada manifestação de um sentimento de angolanidade e sobre os fatos sociais que ocorriam em Angola. Esses escritores são precursores no que se diz respeito à literatura angolana, sua negritude e sua identidade, casos de Nga Muturi (1882), de Alfredo Troni e O segredo da morta (1929), de Assis Junior. A literatura angolana vai adquirindo formas próprias por volta de 1948, libertando-se dos padrões coloniais, exaltando cada vez mais sua regionalização e sua realidade. Aos poucos, os escritores percorrem, dentro do leque social de Luanda, questões como: relações familiares, justiça, hábitos sociais/religiosos, culinária, conceitos morais etc.

É nesse cenário colonial que nasce, no ano de 1941, o escritor Artur Carlos Maurício Pestana dos Santos, mais conhecido como Pepetela. Natural de Benguela, Pepetela passou a sua infância em Angola, mas fez grande parte dos seus estudos em Portugal. No ano de 1958, em plena efervescência angolana pela descolonização, Pepetela inicia suas atividades políticas e culturais na Casa dos Estudantes do Império, em Lisboa. Durante esse período, o escritor estava 
constantemente ligado aos assuntos relacionados ao futuro da nação angolana, e foi exatamente nessa época que ele extraiu um tema muito presente em suas obras: a guerra colonial.

Após o ano de 1950, a produção ficcional angolana ganha um novo espírito coletivo, no qual a ordem é dar uma nova aparência à estética e às questões ideológicas, reafirmando a essência da angolanidade. Por conta dessa nova ordem, os textos procuram registrar um espaço que precisa voltar a ser o que era antes da colonização: a necessidade de reconstruir um país mortificado e destruído. Acompanhando essa estética, diz Laura Cavalcanti Padilha:

Ao invés de um lírico canto-exaltação às belezas exóticas da terra, dentro dos padrões da fala literária já consagrada do colonizador, vai-se revelar a consciência de que é preciso resgatar uma nova fala pela qual a luta de libertação nacional se venha corporificar (PADILHA, 1995, p. 133).

O trabalho em conjunto, visto nos textos ficcionais, pode ser atribuído tanto à voz dos narradores quanto à temática apresentada. A narrativa é tecida por aqueles que estão presenciando um sofrimento de perto, isto é, alguém que nunca deixou a terra amada. As personagens que se apresentam são indivíduos que têm preferência e direitos sobre essa terra. O cotidiano é um tema recorrente nos textos, pois é nele que se tira boa parte dos relatos traçados nas linhas literárias - os musseques de Luanda, as senzalas, aldeias e os quimbos são os ambientes preferidos dos autores. A intenção é avançar na conscientização dos angolanos, e para isso, várias estratégias foram usadas, incorporadas na identidade de personagens, como bem cita Laura Cavalcanti, o homem alienado Mestre Tamoda, do livro que leva o mesmo nome, do escritor Uanhenga Xitu; e o forte comandante Sem Medo, personagem de Mayombe, do livro de Pepetela.

Com bases nas atividades políticas de Pepetela no fim da década de 1950 e início da década de 1960, o leitor já consegue vislumbrar o cunho revolucionário de seus textos. Em 1992, foi publicado o romance $A$ geração da utopia, um romance dividido em quatro partes e narrado ao longo de dez anos, que abarca, no primeiro capítulo, intitulado "A casa", o ano de 1961, período em que os jovens militantes iniciam uma calorosa mobilização para a guerra de libertação de Angola; no segundo capítulo - "A chana" -, o ano é 1972, época que atinge o centro da guerra colonial; o terceiro capítulo - "O polvo" -, inicia-se no ano de 
1982, período que retrata o fim da guerra, logo numa Angola já independente; e por fim, o quinto capítulo - "O templo" -, que começa em julho de 1991.

A efervescência sobre os acontecimentos políticos que envolviam as relações coloniais entre Portugal e Angola era um assunto recorrente para a geração juvenil da época. A narrativa nos apresenta personagens que, na sua maioria, estão envolvidos diretamente com a guerra de libertação. Tanto que no primeiro capítulo o narrador nos apresenta a personagem Sara (muito significativa para o desenrolar da história) como uma jovem com olhar crítico sobre a sociedade portuguesa e a sua fixação pela terra colonizada:

"Convém a Salazar criar o clima de história colectiva, centenas e centenas de brancos trucidados pelos terroristas, Angola é uma fogueira imensa, temos de defender a Pátria e os portugueses. Para Angola em Força! A propaganda estava a resultar, tinha de reconhecer. Um espesso clima de suspeição se abateu sobre os africanos em Lisboa. Passaram a cochichar quando antes discutiam a altos gritos, sempre com gargalhadas no meio. E a população passou de repente a olhá-los com hostilidade.

[...] Nascida em Benguela, feito o final de liceu no Lubango, viera há quase seis anos para Lisboa estudar medicina (PEPETELA, 1995, p. 12).

A personagem Sara é uma das grandes figuras do romance, pois ela, juntamente com Aníbal (personagem que trataremos em seguida), representa essa geração utópica à qual o título se refere. Uma jovem empenhada nas causas de sua pátria. Apesar de ser filha de colonos, Sara é uma jovem decidida com relação ao lado que vai lutar. Mesmo com sua condição mais favorável, ela não se afasta da situação conflituosa que seu país encara. Esse excerto destacado acima nos mostra muito claramente o empenho do governo de Salazar em sedimentar a teoria do terrorismo e a necessidade de combater este câncer social. A partir das ações do governo português, os jovens africanos que residiam em Lisboa se veem obrigados a criar estratégias de sobrevivência e também de articulação de lutas. Sara é a personagem que luta, que se mobiliza pelo amor à Pátria, sem criar limites para as questões raciais ou com os laços familiares portugueses. Ela está sempre com os "pés" nos dois polos: filha de portugueses/namorada de angolano; homens de guerra, representa a figura feminina no processo; a causa toma rumos raciais/ uma garota branca que se envolve com o movimento. 0 
escritor coloca nessa personagem a força que o movimento precisava naquele momento - lutar somente.

A criação dessas estratégias acaba por colaborar ainda mais com a reunião desses jovens africanos, que constroem, no espaço da Casa dos Estudantes do Império, um local de troca de pensamentos, anseios, estratégias e paixões. A casa não só representa o local de construção do cenário de guerra, como também a formação do futuro utópico, ela é, então, um espaço embrionário, onde todas as teorias criadas pelas discussões desses jovens sofrem diversas transformações durante a narrativa.

A literatura é, dentro desse capítulo, uma importante arma de guerra, pois é através dela que as discussões desses jovens ganhavam formas e lógica para as estratégias ali apresentadas. Vejamos:

Foram anos de descoberta da terra ausente. E dos seus anseios de mudança. Conversas na Casa dos Estudantes do Império, onde se reunia a juventude vinda da África. Conferências e palestras sobre a realidade das colônias. As primeiras leituras de poemas e contos que apontavam para uma ordem diferente (PEPETELA, 1995, p. 13).

A relação entre esses jovens e a literatura foi de extrema importância, pois foi a partir da manifestação literária dos jovens angolanos envolvidos na guerra que a conscientização se dissipou. $\mathrm{O}$ olhar crítico dos escritores engajados, aos quais nos referimos nas primeiras linhas deste trabalho, nos alerta para uma relação indissociável entre a literatura escrita em Angola e o movimento de libertação.

Não gratuitamente, os fundadores do Movimento Pela Libertação de Angola - MPLA (fundado em 1956) -, eram escritores comprometidos com a literatura e a política, basta pensar na trajetória de vida e atividade literária de personalidades como Agostinho Neto, António Jacinto, Arnaldo Santos, Luandino Viera e o próprio Pepetela. A relação íntima entre literatura e política fica mais evidente no livro se pensarmos no personagem Horácio, "um mulato que publicara uns poemas no Boletim da Casa, considerados razoáveis para um início, e que agora não perdia uma oportunidade para monopolizar as conversas com literatura" (PEPETELA, 1995, p. 28). Podemos considerar, então, que as palavras escritas se tornaram aliadas dos jovens revolucionários, elas ganharam formas e foram usadas em favor dos ideais sonhados nos anos 1960. E mesmo durante a guerra, 
elas foram "companheiras" dos escritores, é só pensarmos nas obras Mayombe (escrita em 1970/71 e publicada em 1980), um romance polifônico que possibilita a narrativa em plena guerra, ou então, a obra No antigamente, Na vida (escrita em 1967/68 e publicada em 1974), escrita durante o período em que o escritor estava preso no Campo do Tarrafal, em Guiné-Bissau, a obra narra a violência sofrida pelos angolanos em tempos coloniais.

Assim, no momento em que esses jovens da Casa se articulavam para guerrear, eles criavam simultaneamente o cenário literário de Angola (não desconsiderando a atividade literária milenarmente exercida pela linguagem oral através dos griots). O país buscava se libertar da condição de colonizado e também das amarras que prendiam a literatura angolana à literatura portuguesa até então.

Durante o período de 1948 e 1975, o que estava em voga era a literatura e a construção da nacionalidade caminhando juntas (aliadas por uma série de escritores). No mesmo período, surge também a moderna literatura, permeada pelo processo estético e histórico (não podemos nos esquecer que os escritores dessa fase da literatura angolana eram, na sua maioria, jovens universitários em Lisboa que mantinham contato com as literaturas da Europa, e com países com históricos de conflitos coloniais, como Brasil, Argélia, Cuba entre outros), que visavam à consciência da nacionalidade e luta pela descolonização. Esses dois processos estabelecem entre si relevantes simbologias, mesmo depois da independência. Alguns mecanismos, durante a reconquista dos modelos nacionais, vão reaparecer como instrumentos de transformação dos novos padrões estéticos, como a tradição oral, juntamente com o desvio da norma e a nota dissonante, e esses resultados são obtidos através do que Laura Cavalcanti chama de nova fala ficcional "griotizada e griotizante", que são misturas de letra, voz e gesto.

Essas misturas a que acabamos de nos referir têm o intento de fazer com que o povo falasse através do texto, e que também falasse com o texto - isso é chamado de processo de griotização -, o qual resulta na troca de mensagens que o indivíduo possa ter com as letras, e assim, unir-se a elas e ao seu propósito. O destinatário da obra literária muda, não é mais o colonizador ou o intelectual assimilado para ser o colonizado. A escrita griotizada serviu de válvula para unir o texto com o povo, as leituras eram feitas longe dos centros urbanos (uma forma estratégica de fazer com que o texto chegasse somente no foco), pois, no momento histórico da retomada do seu espaço (Angola), o texto necessitava ser pronunciado em alta voz e ser simples para ser armazenado na mente e 
reproduzido pela memória, afinal de contas estamos falando de uma nova face de literatura angolana que retomou os valores dos griots e que, portanto, sua essência tem de ser como a dos velhos sábios contadores de histórias, os quais sabiam muito bem unir a oralidade com as ações transformadoras.

Os produtores dos textos ficcionais não tinham a intenção de que seus textos chegassem apenas ao público interno, diz Laura:

No momento da planetarização cultural do século XX, não se poderia conceber uma literatura que ficasse presa à contingência da luta interna, sem se abrir aos leitores de todo o mundo [...]. Essa dupla destinação fazia com que o escritor mesmo depois da independência - tivesse de usar técnicas e procedimentos que lhe permitissem atingir um e outro público. A língua portuguesa se fez, sem dúvidas, um desses mediadores textuais (PADILHA, 1995, p. 140).

Podemos observar que mesmo havendo uma preocupação com as ações revolucionárias - para também manter as línguas nacionais em voga -, os escritores perceberam que manter e dominar a língua do colonizador seria necessário para atingir um público leitor maior; vemos, então, uma via de mão dupla, isto é, o plurilinguismo da literatura angolana visava a procura da originalidade da cultura autóctone, e também, a manutenção e a exploração da língua do colonizador como estratégia de espargir essa literatura revolucionária.

Toda essa movimentação na Casa mostra o quanto a guerra de libertação era a fonte que alimentava a alma dessas personagens, sobretudo o jovem Aníbal. Este pode ser considerado o grande protagonista da história, ele aparece em todos os capítulos do livro e influencia a todo instante os rumos da narrativa. Jovem sério e comprometido com a causa do seu país, Aníbal mantém uma relação próxima com Sara. E se podemos considerar Sara como a personagem que transpõe barreiras pessoais (durante a narrativa ela passa por diversos conflitos de ordem pessoal) em busca de uma causa coletiva, Aníbal pode ser considerado como a válvula que dá vida ao movimento de libertação, ele participa dos momentos mais importantes para o futuro do país, as discussões na Casa, como a constituição do partido, entra na clandestinidade, vai para chana, até o seu autoexílio no final do livro.

O esse percurso da vida de Aníbal pode ser considerado a trajetória de um herói, isso se pensarmos nas causas que impulsionavam as ações do mesmo. 
Através de Sara, o personagem vai criando formas aos olhos do leitor:

"Um militar estava habituado a essas aventuras, mas Sara nunca o via como militar ou aventureiro. Baixo, magro, sempre agarrado aos livros e às ideias, não era propriamente a imagem que se fazia de um herói" (PEPETELA, 1995, p. 50).

Apesar de Sara não nos narrar que a aparência física de Aníbal não era propriamente a de um herói, o leitor pode considerá-lo como tal, tendo em vista os atributos e valores de um revolucionário. Dentro do contexto inquietante do período colonial, cabe bem ter um herói com características que inquiete o leitor.

O personagem Sábio é a figura mais engajada em todo o processo, seja ele teórico (discussões sobre os rumos da luta armada), ou prático (foi um dos mais reconhecidos guerrilheiros). O próprio apelido que ganha representa o nível da sua maturidade - Sábio - apelido que ganha durante a sua participação na guerrilha. A narrativa nos mostra que Aníbal representa a essência do coletivo, suas ações estão sempre voltadas para uma causa maior, a sua liberdade não é fechada em si, mas recai no coletivo. $O$ autor cria um personagem com ideais inflexíveis, ele mantém a sua posição incorruptível do início ao fim da narrativa. Com uma visão crítica e realista daquilo que o movimento e a guerrilha de libertação se tornou, através de seu olhar e fluxo de pensamento, o leitor entra em contato com o universo pós-colonial angolano. E diante desse acesso, conseguimos vislumbrar as mazelas da sociedade angolana da década de 1990. Toda organização e discussão iniciada durante as reuniões na Casa são descontruídas no processo de libertação e pós-1975. O personagem nos faz saber que a corrupção é um fato muito natural:

Como todos, enquanto são dirigentes. São todos capazes e honestos, sem excepção. Quando um deixa de ser dirigente, então é que se sabe que afinal era um incompetente e um corrupto. A mitologia do poder, ou a mitificação dos homens do poder. Passa-se em qualquer religião ou seita, $O$ chefe da seita é um santo, um desinteressado, adorado pelos fiéis. Quando cai, descobre-se que era o diabo e tem uma conta secreta na Suíça com milhões. Tudo isso é tão antigo e repete-se sempre em todos os regimes. Mas as pessoas não vêem, porque acham que a sua experiência é única e melhor que as outras. Uma fé como religiosa. Ora, uma fé não se combate, nem por explicações racionais (PEPETELA, 1995, p. 201). 
Assim, a desconstrução do universo utópico é atribuída a Aníbal, que na escoIha de se autoexiliar em Benguela, priva-se também de usufruir dos benefícios conseguidos por poucos através da governança do país. Com isso, percebemos que a reprodução de formas de governo não valeram para a administração de Angola, isto é, o país deixa de ser colônia de Portugal, mas continua vivendo as mazelas da má administração, agora liderada pelos intelectuais angolanos, a corrupção se torna um fator presente na nova governança. Diante desse cenário, Aníbal não nos mostra uma possibilidade de mudança, porém, a visão crítica da juventude do país, projetada pelos personagens Orlando e Judite (filha de Sara), que possibilita a renovação do fôlego e uma crença no futuro.

Para falarmos das possíveis mudanças administrativas de Angola representadas pelos dois jovens personagens ditos no parágrafo acima, não podemos nos esquecer que eles enfrentaram um embate com dois representantes da ordem contrária - Malongo e Vítor - estes podem ser considerados os antagonistas. Dois personagens que durante a narrativa apresentam desvio de compromissos, usurpadores no poder administrativo (Vítor) e comercial (Malongo) da Angola independente, ambos são representados no final da narrativa com uma posição favorável, o que nos faz comparar com a vida simples de Aníbal, afinal, diferentemente de contos de fadas, o que nos parece é que aqui Pepetela, através de uma narrativa clara, desenha os antagonistas com uma posição mais "confortável” que do próprio herói Aníbal. Sobre Malongo, o narrador nos diz no último capítulo:

Tinha começado há sete anos. Nos últimos tempos, só tratava de negócios grandes, recusava representar as firminhas com que iniciara. Agora nadava no meio dos tubarões e recebia grandes postas dos peixes caçados, já não se contentava com uma sardinha. [...] Ele agora é que ia escolher os produtos e as tecnologias que queria introduzir no país (PEPETELA, 1995, grifo nosso, p. 261).

E sobre Vítor ele diz:

Mundial tinha abandonado a mulher que trouxera da mata e dos filhos, um ano depois de se fixar em Luanda. Seis meses após ascender ao cargo de Ministro, reparou na Luzia [...] Luzia quis mais e conseguiu, casamento com muitos convidados e grande boda fornecida por uma empresa estrangeira (PEPETELA, 
1995, grifo nosso, p. 266).

A partir desses excertos o leitor consegue vislumbrar a diferença de vida entre Aníbal, Malongo e Vítor. De certa forma, a maneira como Malongo usufrui do poder não é admirável os olhos do leitor, tendo em vista a maneira apolítica e displicente com que ele levou a vida desde o primeiro capítulo, contudo, a opção de vida de Vítor é contrastante com o Vítor do primeiro capítulo, há uma espécie de mutação de personalidade, a experiência dele como Mundial (nome de guerra) faz com que ele altere não só o nome, mas também a crença nos valores coletivos. Nos excertos anteriores, percebemos um Malongo cheio de poder econômico e ambicioso, já no segundo trecho, temos um Vítor que chega ao poder rapidamente, é coroado ministro em apenas seis meses, o que nos mostra que a burguesia angolana pós-colonial possui também em sua estrutura representantes políticos descomprometidos com os valores da terra, fator tão buscado nos tempos da Casa.

Por fim, o leitor se dá conta de que todas as estratégias políticas e administrativas do país discutidas anteriormente na Casa dos Estudantes do Império não passaram de teorias do imaginário. A realidade não deu conta de deixar sobreviver os sonhos de outrora. $\mathrm{O}$ espaço da Casa é o local onde se alimentava as utopias daquela geração de jovens militantes, mas, durante a narrativa, os capítulos passam por uma travessia de tempo e espaço, e durante esse trajeto, alguns desejos começam a ser descontruídos na "Chana", e quando chegam no "Templo" não restam muitos anseios positivos para o país. Como num processo que vai da utopia de jovens revolucionários à distopia de adultos segregados, o escritor finaliza a sua obra, deixando ao leitor a decisão de acreditar numa possível renovação dos interesses coletivos tão dominantes no início da obra. 


\section{Referências Bibliográficas}

FANON, Frantz. Os condenados da terra. Rio de Janeiro: Civilização brasileira, 1968.

FERREIRA, Manuel. Literaturas Africanas de expressão portuguesa I. Portugal: Biblioteca Breve, 1977.

LIMA, Isabel Pires de. "Em busca de uma nova pátria: o romance de Portugal e de Angola após a descolonização”. In: Revista Via Atlântica. São Paulo: Universidade de São Paulo, no. 1, 1997, p. 129-141.

PADILHA, Laura Cavalcante. Entre Voz e Letra: o lugar da ancestralidade na ficção angolana do século XX. Niterói: Editora da Universidade Federal Fluminense - EDUFF, 1995.

PEPETELA. A Geração da Utopia. Lisboa: Publicações Dom Quixote, 3ạed. 1995.

VECCHI, Roberto. Expecção Atlântica. Pensar a Literatura da Guerra Colonial. Porto: Edições Afrontamento, 2010. 